\title{
Violence against physicians and nurses: a systematic literature review
}

\author{
Sayantan Chakraborty ${ }^{1}$ Saidur Rahman Mashreky ${ }^{2} \cdot$ Koustuv Dalal $^{3}$ (i)
}

Received: 21 April 2021 / Accepted: 13 December 2021 / Published online: 22 January 2022

(c) The Author(s) 2022

\begin{abstract}
Background Violence against physicians and nurses is a global public health problem. This study explored violence against physicians and nurses using a systematic literature review.

Methods Pubmed and Scopus were searched using search words 'violence' OR 'aggression' 'against' 'physicians' AND 'nurses'. Articles published between 2010 and 2020 in the English language, excluding review/systemic review articles, were included in the study. We used the Preferred Reporting Items for Systematic Reviews and Meta-Analyses (PRISMA) guidelines for literature search and reporting and assessed the quality of the article based on the JBI checklist for analytical cross sectional studies.

Results A total of 22 studies were included. The majority of the studies showed that there was a significant violent incident within every setting, often directly involving patients or their relatives. Workers of emergency departments were more likely to be exposed to violence. Verbal abuses were the highest among all settings. Physicians were more likely to face physical violence, while nurses were more prone to sexual harassment. Lack of communication plays a significant role. Fewer reports of violence were noted due to lack of action taken previously.

Conclusion Adequate policy making and implementation and operational research are required to further mitigate the episodes of violence.
\end{abstract}

Keywords Violence $\cdot$ Physician $\cdot$ Nurses $\cdot$ Healthcare $\cdot$ Systematic review

\author{
Abbreviations \\ UK United Kingdom of Great Britain and Northern \\ Ireland. \\ ICU Intensive Care Unit.
}

\section{Background}

Violence against physicians and nurses, along with other healthcare personnel, is not a new phenomenon (McKay et al. 2020). Various violent incidents were widely

Koustuv Dalal

koustuv.dalal@miun.se; koustuv2010@hotmail.com

1 Kolkata Haematology Research Initiatives (KHERI), Kolkata, India

2 Centre for Injury Prevention and Research Bangladesh (CIPRB), Dhaka, Bangladesh

3 Division of Public Health Science, School of Health Sciences, Mid Sweden University, Sundsvall, Sweden, and School of Medicine and Health Care, al-Farabi Kazakh National University, Almaty, Kazakhstan documented worldwide (WHO 2016). An Iranian study indicated that healthcare personnel are 16 times more exposed to violence at their work settings (Najafi et al. 2014). This situation is not only found in middle-income countries, similar incidents happen in high-income countries such as Australia (Hills et al. 2012), the UK (Elston and Gabe 2016), Germany (Vorderwülbecke et al. 2015), and many more. Although every nation has taken a variety of measures to prevent such events, similar incidents continue to occur due to various causes. According to a research paper published from India, some causes of such incidents were low social image of the doctors, the role of media, low health budget constraints and low quality of healthcare. The study also indicated that vulnerability of small and medium private healthcare facilities, lack of faith in the judicial process, low health literacy, huge cost of healthcare and poor service provider-seeker communication trigger the problem (Nagpal 2017). In this Covid-19 context, to prevent workplace violence against healthcare workers, India has passed a new law (Withnall 2020). The patient-physician, along with other healthcare professional relationships, is the keystone of the healthcare delivery system (Agarwal 2017). Therefore, such violent activities are 
the proxy indicators that a nation has a flawed healthcare delivery system. This review paper provided evidence on the prevalence of different violent activities upon physicians and nurses and their particular characteristics, which will help to devise prevention strategies.

\section{Methods}

The current study has used the Preferred Reporting Items for Systematic Reviews and Meta-Analyses (PRISMA) guidelines for literature search and reporting (Moher et al. 2009). One junior researcher and one senior researcher independently searched scientific literature in November 2020 in two databases viz. PubMed and Scopus using search terms, 'violence' OR 'aggression' 'against' 'physicians' AND 'nurses'. Studies published in English during the past ten years (2010-2020) were screened for inclusion. Eligible studies, both quantitative and qualitative, focused on violence or aggression against physicians or nurses or both were included. Studies related to other healthcare workers along with physicians or nurses or both were also included. Systemic reviews and review studies were excluded.

One senior researcher rechecked data and consensus by repetitive meetings to resolve all the disagreements and discrepancies. In total, 66 articles were found based on the search strategy in Pubmed and 1360 in Scopus. Among them, after removing duplicates, only 912 articles were selected. Among those articles, 538 were included after excluding non-English, review/systemic review articles, selecting articles published in the past ten years, and selecting fields social science \& medicine. Among them, 516 articles were excluded because those articles did not meet the objectives upon which this review study was conducted. Therefore, finally, 22 articles were included for review. The exclusive screening and acceptance process is described in Fig. (1).

The current study focused on and included the author's name, year of publication, place of study, country, year of study, study type, population, sample size, demographic data, type of violence, prevalence of different types of healthcare workplace violence, vulnerable areas within settings, persons involved in violence and violence initiation, reporting and consequences and suggested strategies.

Three researchers critically assessed the quality of the selected articles based on the JBI checklist for analytical cross sectional studies (Moola et al. 2020). During critical appraisals of the studies, the one junior and one senior researcher independently identified eight broad themes. Another senior researcher rechecked and validated the themes to explore the factors affecting violence against physicians and nurses. All selected articles were presented denoting whether each of them had dealt with those themes.

\section{Results}

Included articles were arranged chronologically according to the year of publication shown in Table 1. The main findings of those articles were written down under the 'results' and 'conclusions' columns of Table 1 .

Among those selected studies, 18 studies were cross-sectional, three were qualitative and one study was from the mixed-method domain. Among 22 studies, 18 studies were conducted with physicians and nurses, three studies with nurses and only one study with physicians. Male participants outnumber female participants, if all studies are take into consideration. All studies support that violence was a common phenomenon in all the settings. The majority of the respondents indicated that they were exposed to at least one type of violence in their hospitals during the previous 12 months. There were mainly two types of violence that occurred in the hospitals, viz. non-physical and physical. Non-physical violence mainly includes verbal abuse and threats and physical violence includes direct physical attacks upon health workers. Men were more exposed to physical violence than women healthcare staff. From the angle of sexual harassment, women were more exposed. One study revealed that verbal abuses were more common against married, unhealthy and older nurses (Honarvar et al. 2019). In every setting, there were fewer reports against violence than the prevalence of violence. Tjhe main findings of the included studies were arranged in a tabular fashion according to the date of publication.

This study has identified eight broad areas where the articles are reporting or focusing. The areas are Types and prevalence of violence, Vulnerable groups, Place of violence in health facilities, Source of violence initiation, Causes of violence, Reporting of violence, Consequences, Mitigation strategies.

Table 2 presents the assessment of the quality of the selected articles based on the JBI checklist for cross sectional studies. Our assessment shows that not a sigle study had clearly identified the confounding factors and therefore did not mention strategies to deal with confounding factors. For seven studies, we could not assure that the outcomes were measured in a valid and reliable way.

Table 3 presents the conformity of the selected articles with contracted themes. The majority of the selected articles had the following themes, i.e. 'type and prevalence of violence (17 articles)', 'vulnerable groups (13 articles)', 'source of violence initiation (12 articles)' and 'causes of violence (10 articles)'. Less conformed themes were 'reporting of violence (8 articles)', 'consequences (6 articles)', 'place of violence in health facilities (4 articles) and 'mitigation strategies' (3 articles).

\section{Discussion}

There was a significant violent incident within every setting. Patients and patient relatives were directly involved. Workers of emergency departments were more likely to be exposed 


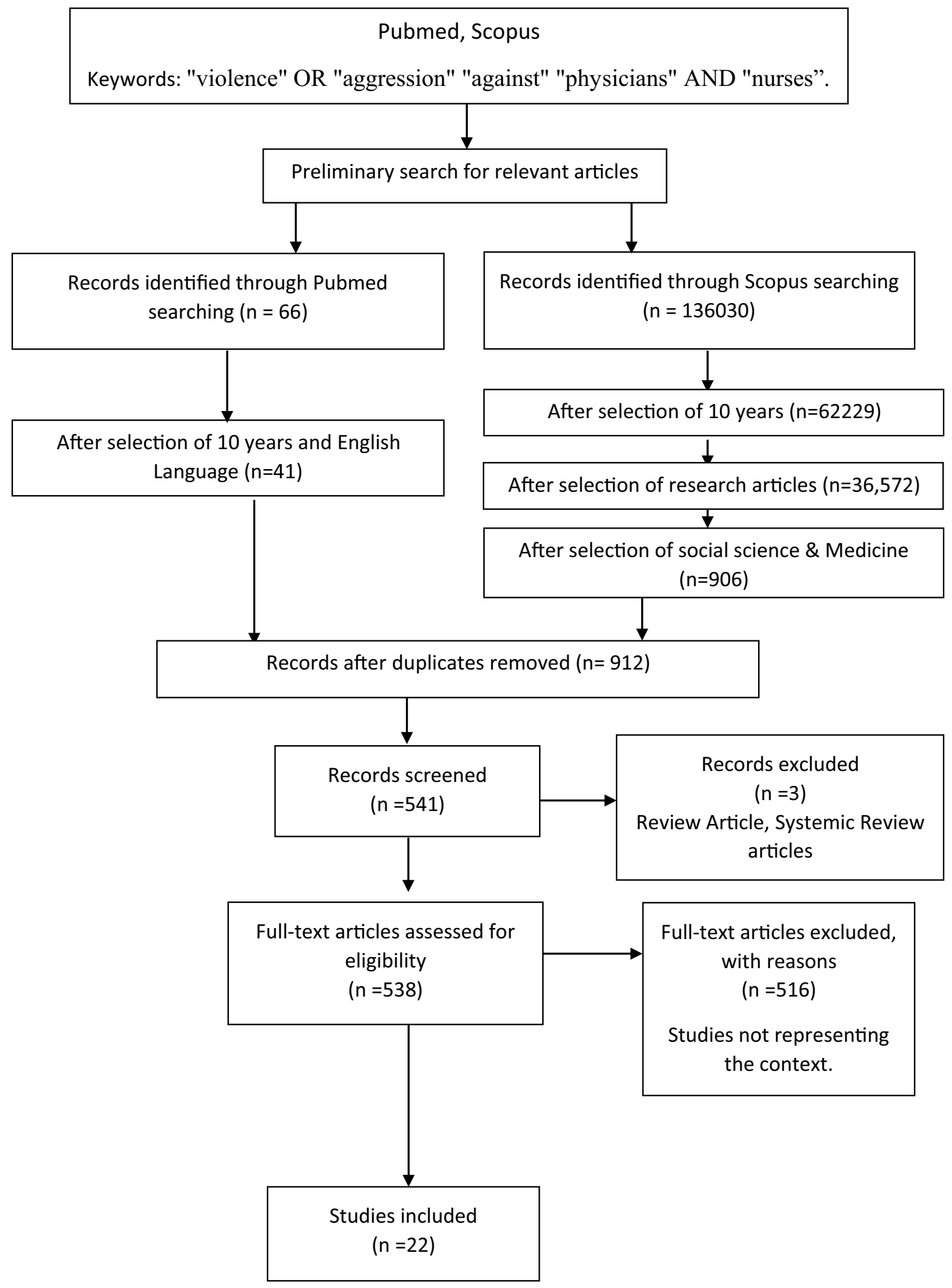

Fig. 1 Hierarchicalarticles screening in two search engines and keywords (PRISMA)

to violence. Verbal abuses were the highest in all settings. Physicians were more likely to face physical violence, while nurses were more prone to sexual harassment. Lack of communication plays a significant role. Fewer reports of violence were noted due to lack of action taken previously. 


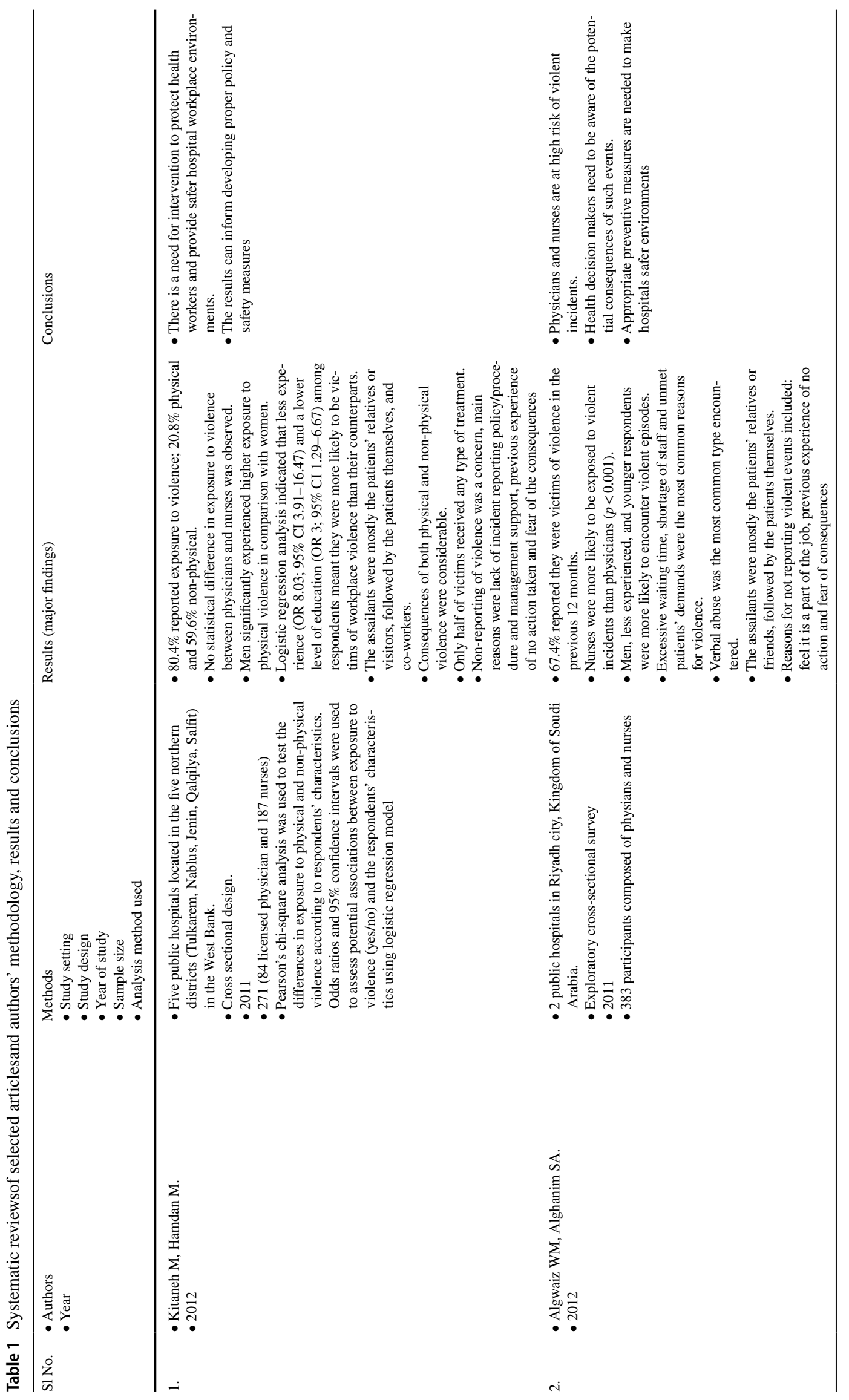




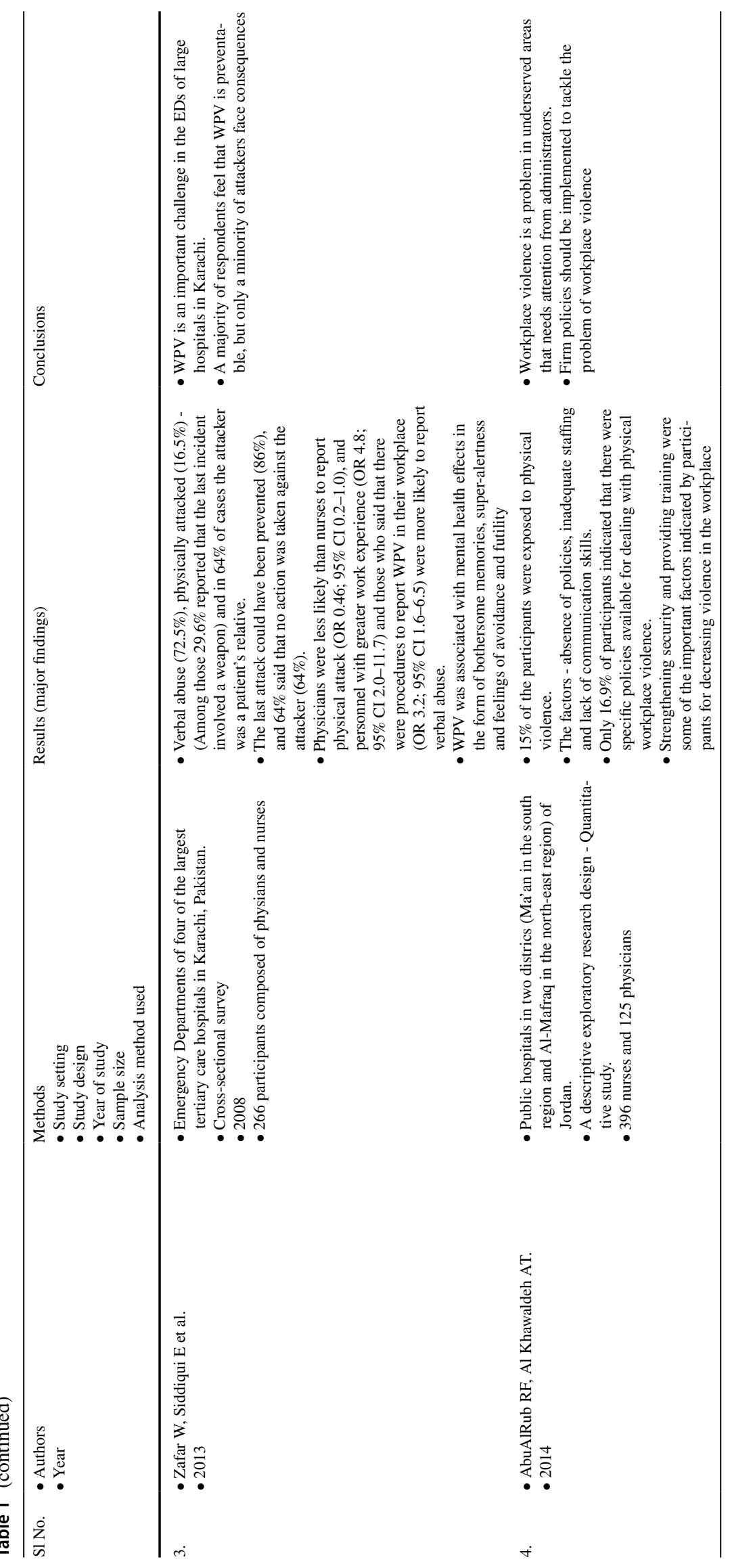




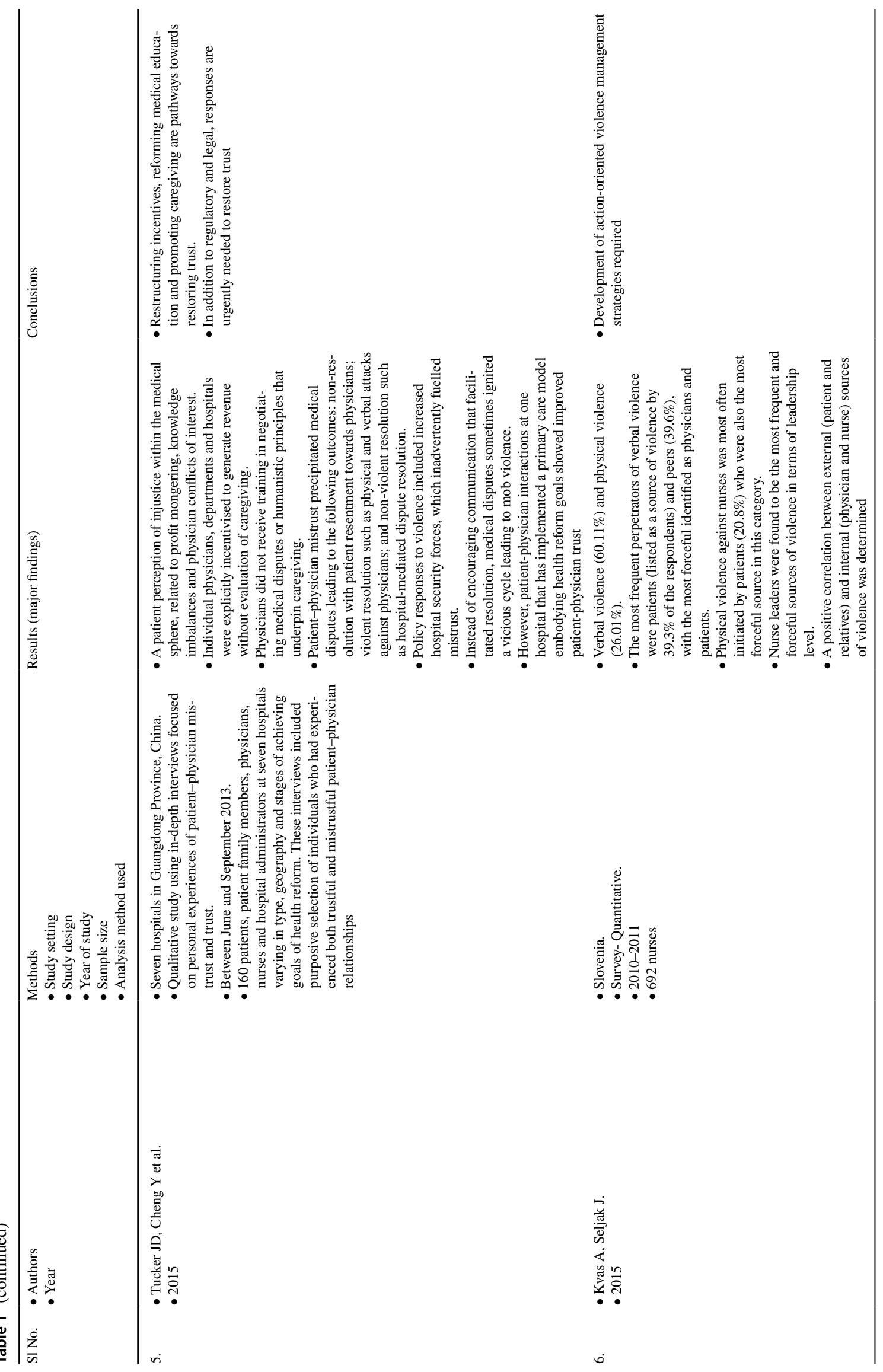




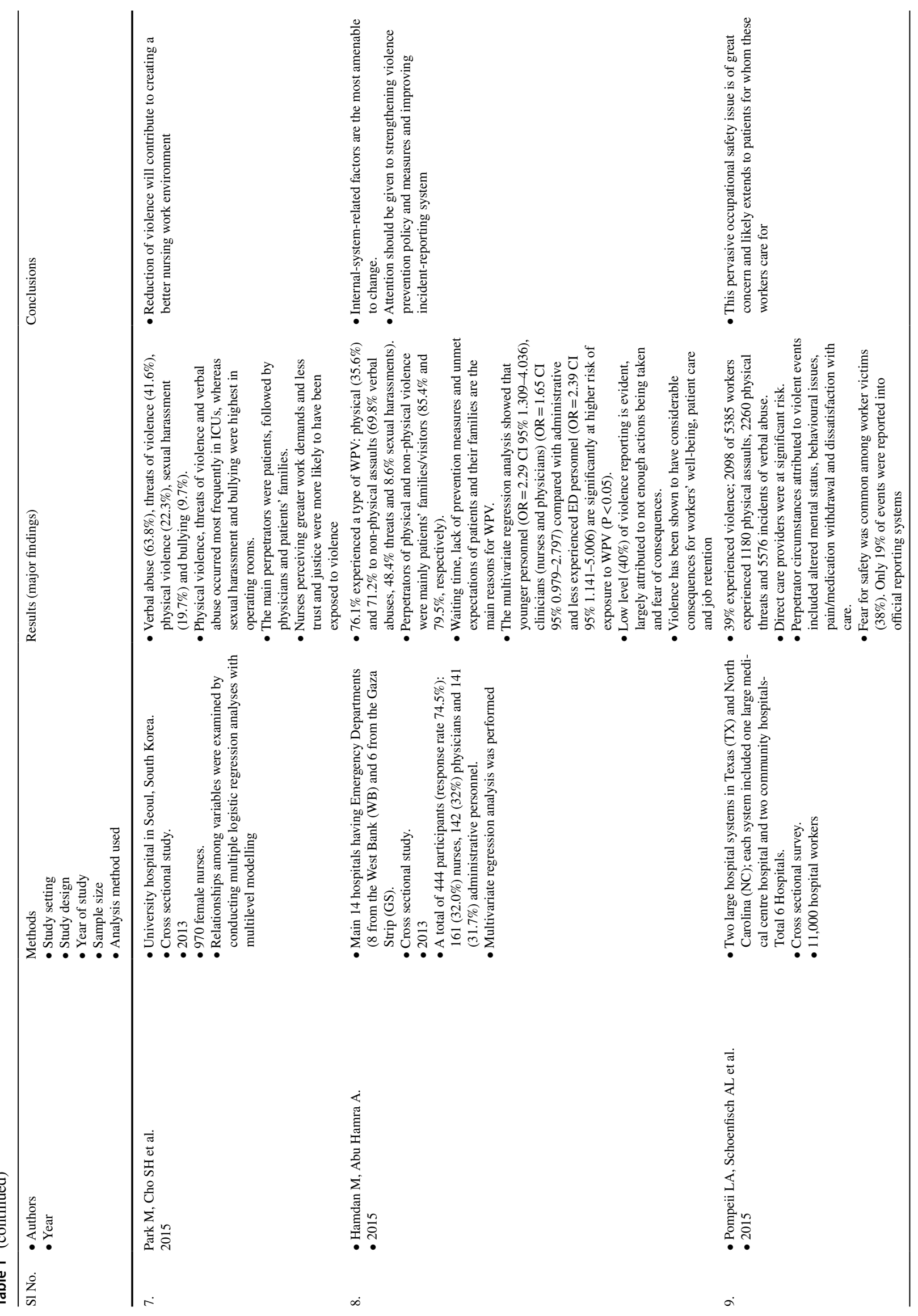




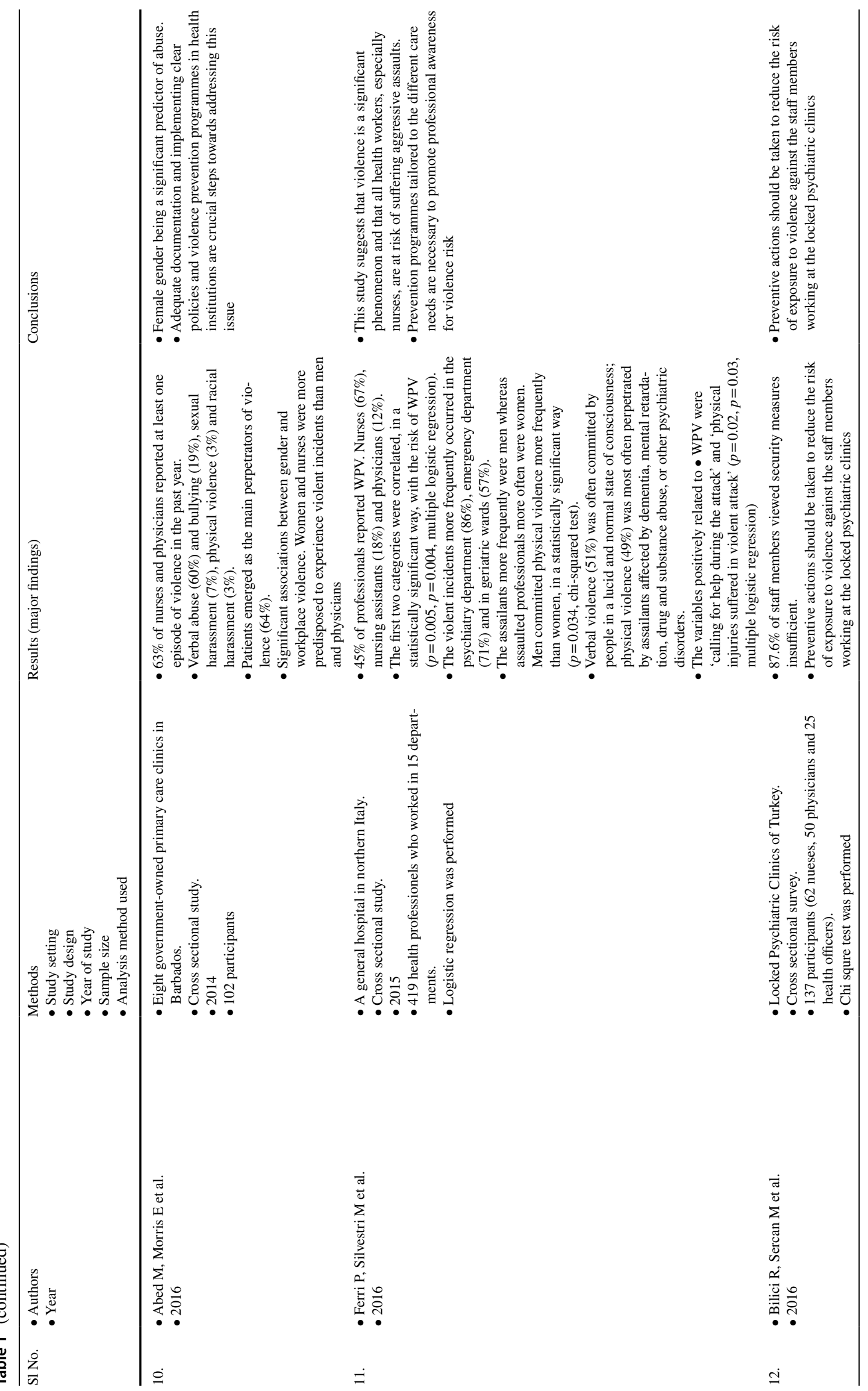




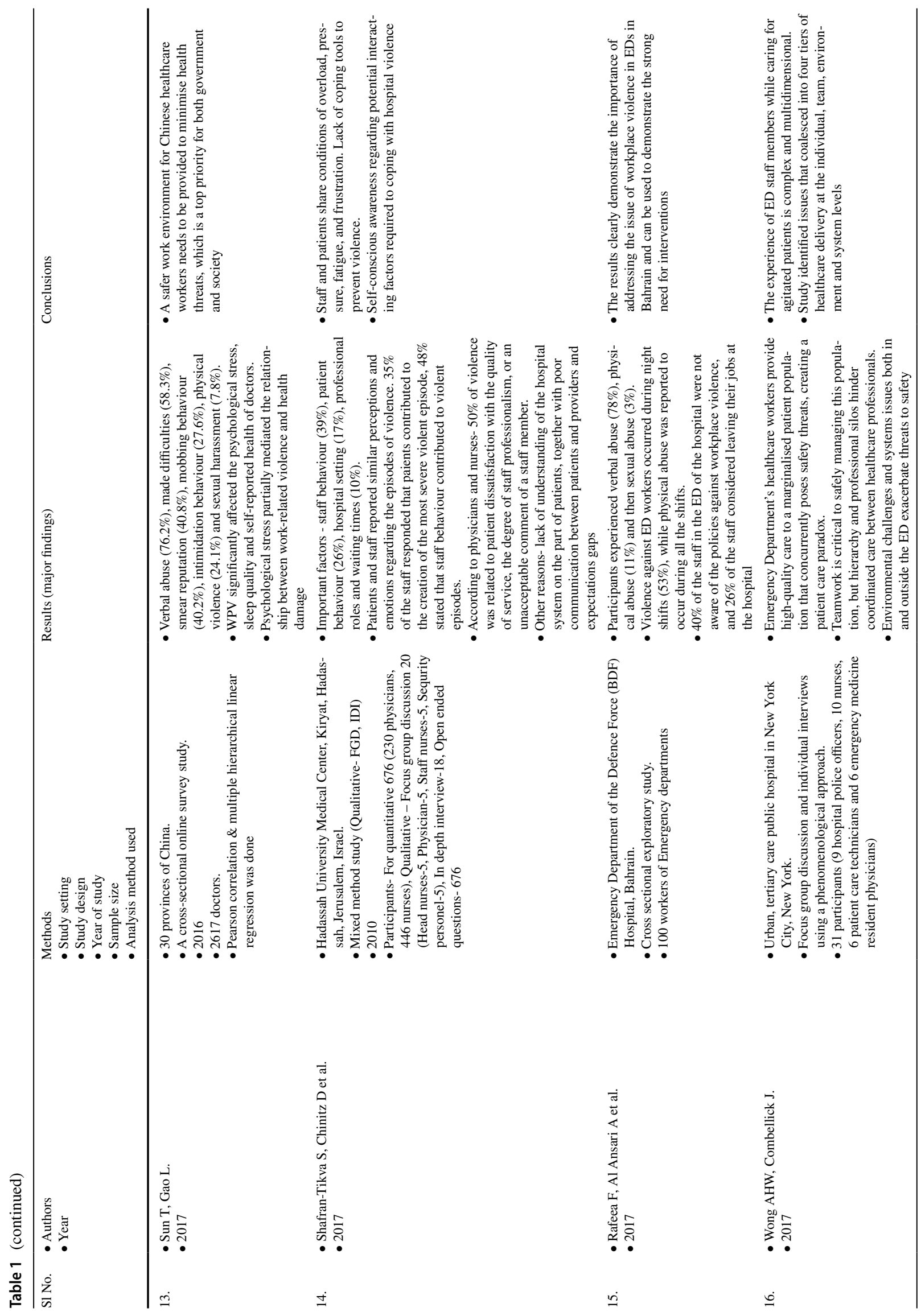




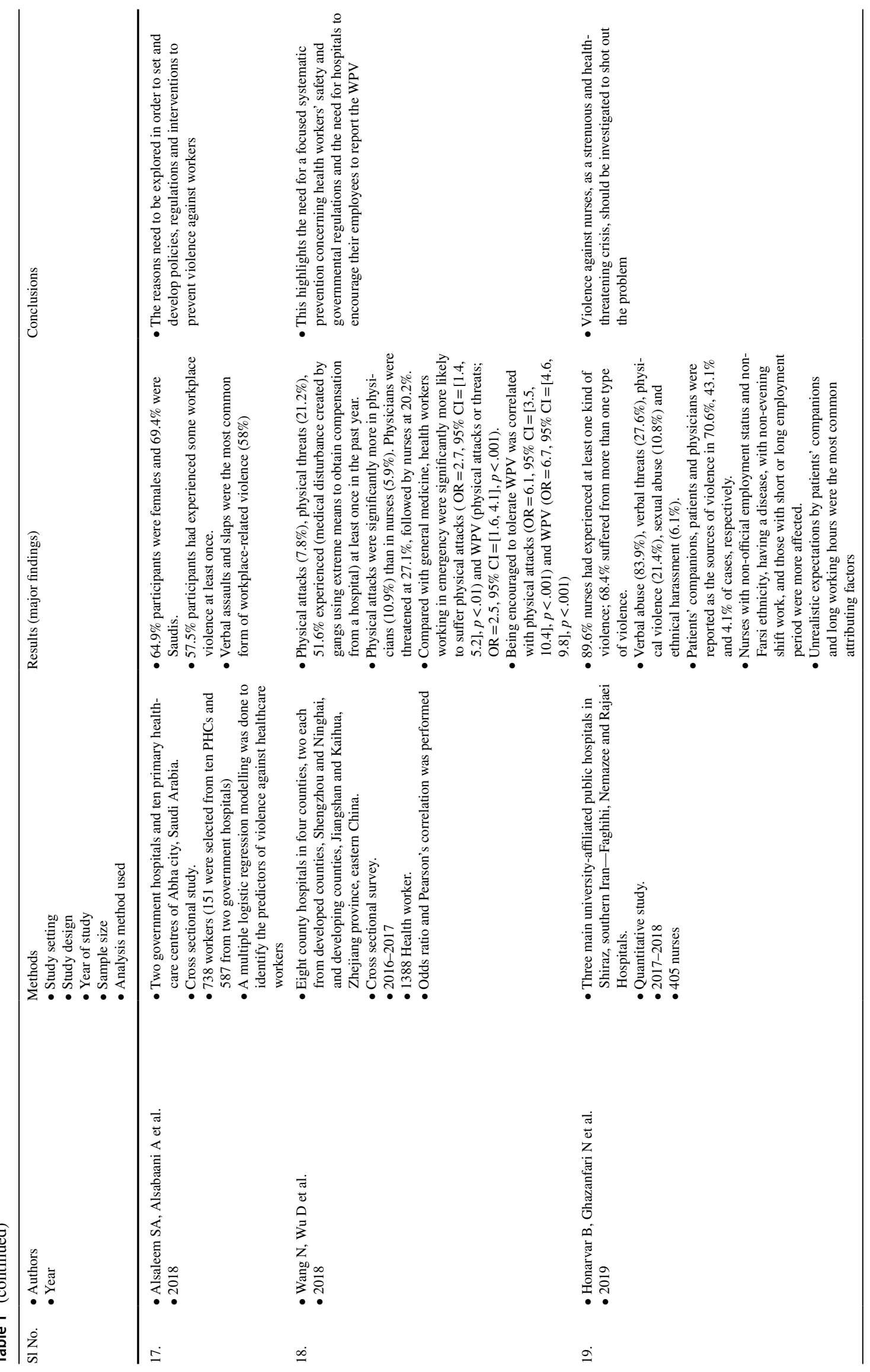




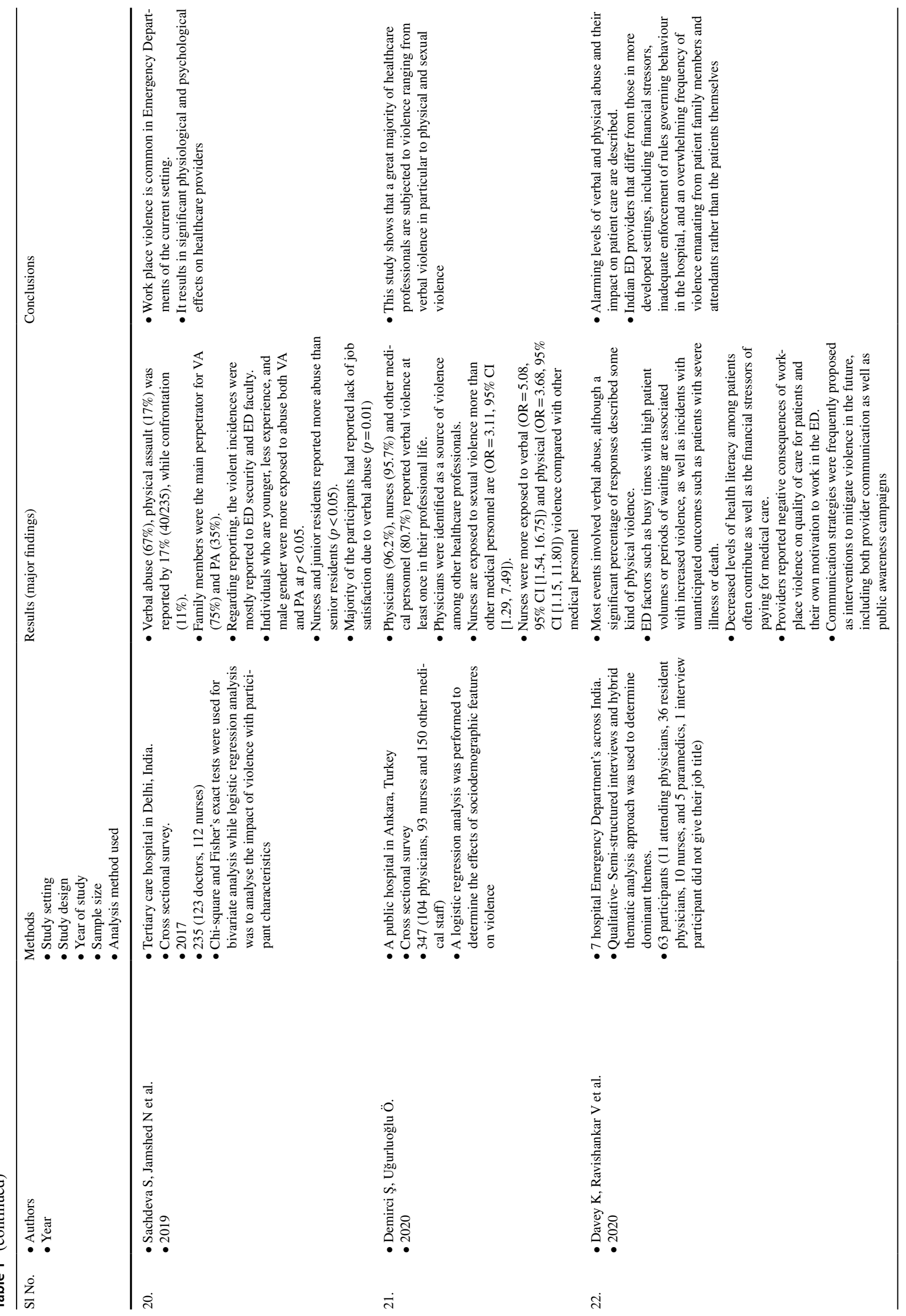




\section{Themes}

The current study identified eight significant themes based on the review articles. Themes were arranged systematically as type and prevalence of violence, vulnerable group, area of violence, source of violence, causes of violence, reporting of violence, consequences of violence and mitigation strategies.

\section{Type and prevalence of violence}

The majority of the participants in different studies agreed that they faced at least one kind of violent attack in the past 12 months. Significant violence were non-physical assaults, followed by physical assaults. Studies showed that according to prevalence, the most common type of violence was verbal abuse, as indicated in various study settings. Other types of violence were verbal threats, physical assaults, sexual abuse, ethnical harassment, reputation smearing, mobbing behaviour, bullying, intimidation behaviour and racial harassment. Some studies showed that sexual violence was higher than physical violence (Abed et al. 2016), and some showed the opposite (Sun et al. 2017). According to one study, patient's and staff's perceptions and emotions regarding violence episodes were similar (Shafran-Tikva et al. 2017). A systemic review and meta-analysis conducted by Liu et al. (2019) showed that $61.9 \%$ reported exposure to any form of work place violence such as exposure to non-physical violence was $42.5 \%$ and $24.4 \%$ experienced physical violence during the previous 12 months. The most common form of nonphysical violence was verbal abuse, followed by threats and sexual harassment (Liu et al. 2019). A systemic review and meta-analysis showed similar results that the prevalence of verbal abuse against the emergency department nurses was 89.7\% and physical violence was 21.0\% (Azami et al. 2018).

\section{Vulnerable groups}

Studies showed that direct care providers were at significant risk (Pompeii et al. 2015). The majority of the studies showed that nurses and women were more likely to be exposed to violence than physicians and men (Algwaiz and Alghanim 2012; Park et al. 2015; Abed et al. 2016; Ferri et al. 2016; Alsaleem et al. 2018; Honarvar et al. 2019; Demirci and Uğurluoğlu 2020). However, another study observed no significant difference between physicians and nurses regarding the episodes of violence (Kitaneh and Hamdan 2012). Physicians and men were more likely to be exposed to physical violence (Kitaneh and Hamdan 2012; Abed et al. 2016; Wang et al. 2018). Nurses and women were more likely to be exposed to sexual harassments (Demirci and Uğurluoğlu 2020). Though one study said physicians were less likely to be exposed to physical attack than nurses (Zafar et al. 2013). Younger and less experienced groups were more exposed to violence than seniors (Kitaneh and Hamdan 2012; Hamdan and Abu Hamra 2015; Sachdeva et al. 2019). However, one study indicated healthcare personnel with more significant work experience were more likely to report verbal abuses (Zafar et al. 2013). Commonly, emergency workers faced violence during the night shift, but workers faced violence in all shifts in other departments (Rafeea et al. 2017).

Vulnerable groups were exposed to violence more due to having less experience regarding better handling the situation, while seniors said their political influence and respect from patients and relatives because of their long years of experience play a significant role (Anand et al. 2016; Kumar et al. 2016; Phillips 2016).

\section{Place of violence in health facilities}

Studies showed that verbal abuse, threats of violence and physical violence most frequently occurred in ICUs, whereas reported highest cases of sexual harassment and bullying were in operating rooms (Demirci and Uğurluoğlu 2020). Those who worked in psychiatry departments, emergency departments, i.e. those who provide a high quality of medical care, and geriatric departments were more likely to be exposed to physical violence (Ferri et al. 2016; Wong et al. 2017; Alsaleem et al. 2018). A systemic review and meta-analysis showed that psychiatry and emergency departments were the most common workplace violence areas (Liu et al. 2019). Another review study supports that emergency departments had a possible chance of becoming a place of violence because of various environmental risk factors of violence such as poor staffing, lack of privacy, overcrowding and availability of nonsecured equipment types that can be used as a weapon (Stowell et al. 2016).

The number of beds in the department in which the critical patients are admitted is usually fewer. Explanation of the patient's particular situation is not always possible by doctors and nurses in those departments due to time constraints and many more related factors. Owing to this, there is more misunderstanding between patient parties and service providers in those departments. The majority of the outcome of those departments' cases were low due to the patient's critical condition leading to more violence in those departments.

\section{Source of violence initiation}

The majority of the studies showed that patients, patient relatives, peers and family members were the main perpetrators of violence (Algwaiz and Alghanim 2012; Kitaneh and Hamdan 2012; Hamdan and Abu Hamra 2015; Kvas and Seljak 2015; Park et al. 2015; Abed et al. 2016; Sachdeva 
et al. 2019). One of the studies revealed the main perpetrators of violence against nurses were the patient and higher authority and a positive correlation between external, i.e. patient and relatives, and internal, i.e. physician and nurse sources of violence (Kvas and Seljak 2015). Along with the above, physicians also identified as a source of violence among other healthcare providers (Honarvar et al. 2019; Demirci and Uğurluoğlu 2020). Staff behaviours also contributed as a source of violence (Shafran-Tikva et al. 2017). Violence was associated with mental health effects as bothersome memories, super-alertness, feelings of avoidance and futility, etc. Patients affected by dementia, mental retardation, drug and substance abuse, or other psychiatric disorders were more involved with violence (Zafar et al. 2013; Ferri et al. 2016).

\section{Causes of violence}

Most of the studies showed that excessive waiting time was the most common attributor of violence against healthcare staff (Algwaiz and Alghanim 2012; Hamdan and Abu Hamra 2015; Shafran-Tikva et al. 2017; Davey et al. 2020). Other factors were unrealistic expectations from patient parties (Hamdan and Abu Hamra 2015; Shafran-Tikva et al. 2017; Honarvar et al. 2019; Davey et al. 2020), poor understanding by the patients and their families of the healthcare system, poor communication between patients and service-providers (Hamdan and Abu Hamra 2015; Tucker et al. 2015; Shafran-Tikva et al. 2017), lack of communication skills among healthcare providers (AbuAlRub and Al Khawaldeh 2014; Hamdan and Abu Hamra 201515; Tucker et al. 2015), behaviour (Pompeii et al. 2015; Shafran-Tikva et al. 2017), condition of a hospital setting (Shafran-Tikva et al. 2017; Wong et al. 2017), staff professionalism, including their unacceptable comments and clients dissatisfaction about the quality of services (Pompeii et al. 2015; Shafran-Tikva et al. 2017), absence of policies, inadequate staff (Algwaiz and Alghanim 2012; Bilici et al. 2016) and long working hours (Honarvar et al. 2019). Another systemic review found a similar result that major risk factors of violence were long waiting times, the discrepancy between patients' expectations and services, substance abuse by the patient and their psychiatric conditions (Raveel and Schoenmakers 2019). Another review study indicated that patients' psychological health, including anxiety, acute stress reaction, alcohol and drug intoxication and dementia, were predictors of physical violence against healthcare workers perpetrated by patients (D'Ettorre et al. 2018).

\section{Reporting of violence}

Violence was most often reported by security personnel and emergency department staff (Sachdeva et al. 2019). Lack of violence reporting was present in every setting. One study showed that only $19 \%$ of violent incidents were reported (Pompeii et al. 2015). The review revealed that physicians and nurses were not interested in reporting violence due to various reasons such as the previous experience of no action taken and fear of the consequences and lack of management support (Algwaiz and Alghanim 2012; Zafar et al. 2013; AbuAlRub and Al Khawaldeh 2014; Hamdan and Abu Hamra 2015). They were not aware of reporting policy \& procedures (Kitaneh and Hamdan 2012; Rafeea et al. 2017).

\section{Consequences}

Owing to consequences of violence, healthcare providers reported lack of job satisfaction. According to one study, $26 \%$ of the staff considered leaving their job at the hospital (Rafeea et al. 2017; Sachdeva et al. 2019). Workplace violence significantly affected the psychological stress, sleep quality and health worker-patient relationship significantly, ultimately affecting the quality of patient care services (Hamdan and Abu Hamra 2015; Tucker et al. 2015; Sun et al. 2017; Davey et al. 2020). Similar findings were shown in a systemic review and meta-analysis conducted by Binmadi and Alblowi (2019) that the impact of violence on workers manifested as impaired quality of work, psychological problems, and, although rare, quitting the job. Another review study conducted by Baydin and Erenler (2014) showed a similar result that workplace violence victims' most common psychological effects were reduced job satisfaction and fear.

\section{Mitigation strategies}

Prevention strategies should be taken to reduce the violent attacks against physicians and nurses and other healthcare providers, mainly those who work in emergency departments (Bilici et al. 2016). Strengthening security personnel and training to mitigate workplace violence among providers is required (Tucker et al. 2015). Communication strategies should be devised as well as public campaigns required to nullify the communication gaps (Davey et al. 2020). Similar mitigation strategies were expressed by the findings of a systemic review and meta-analysis that governments, policymakers and health institutions need to take actions to address work place violence towards healthcare professionals globally (Liu et al. 2019). However, another systemic review and meta-analysis showed no hard evidence on the effectiveness of that (Raveel and Schoenmakers 2019). A qualitative metaanalysis conducted by Ashton et al. (2018) recommended similar findings to reduce workplace violence staff training in understanding violence and aggression and clinical supervision needed. Along with the above, another review study conducted by Gillespie et al. (2010) suggested other 


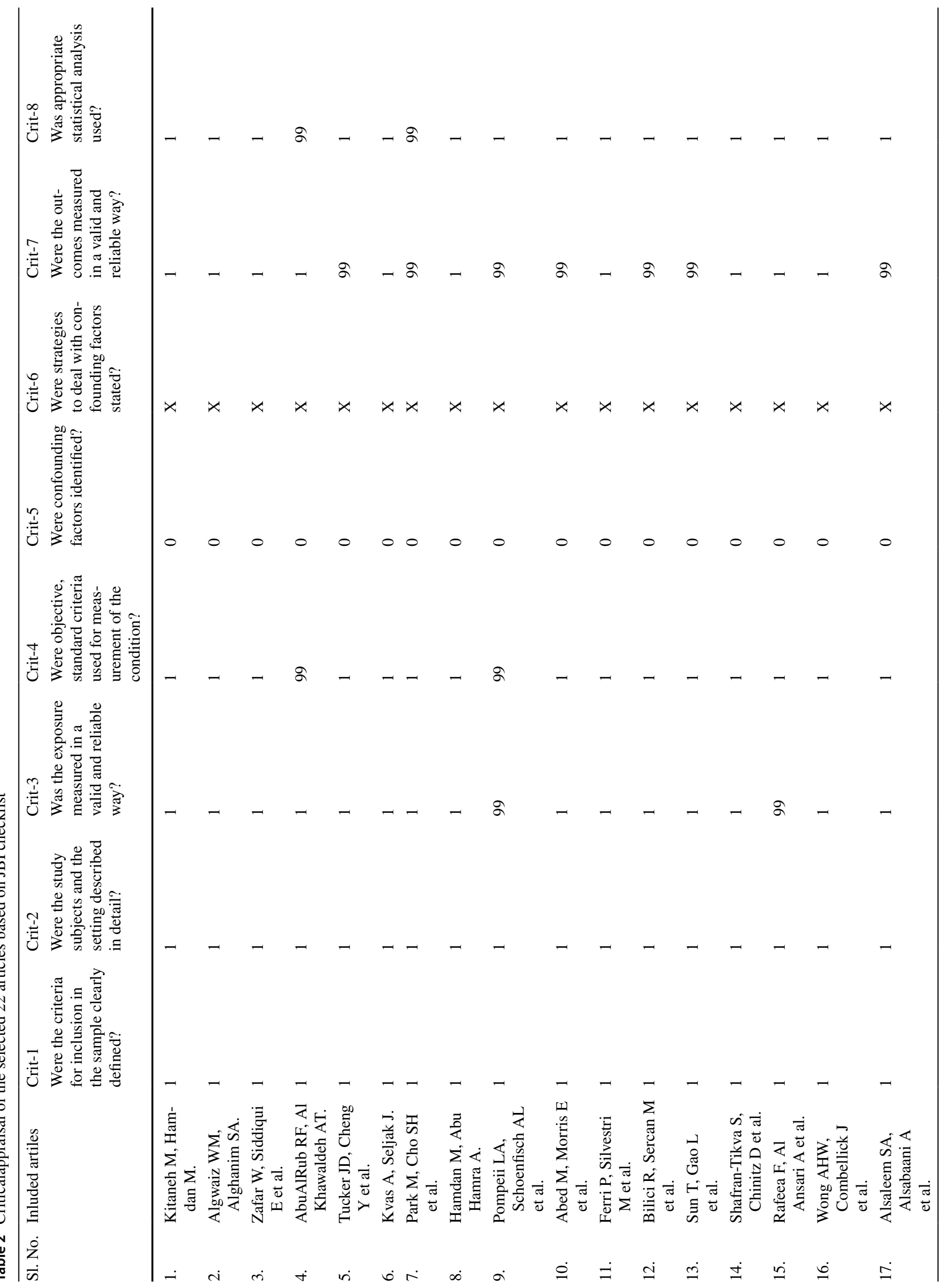




$$
\bar{L}
$$


Table 3 Articles' concepts and themes

\begin{tabular}{|c|c|c|c|c|c|c|c|c|}
\hline $\begin{array}{l}\text { Themes Studies (author } \\
\text { names) }\end{array}$ & $\begin{array}{l}\text { Types and } \\
\text { prevalence of } \\
\text { violence }\end{array}$ & $\begin{array}{l}\text { Vulner- } \\
\text { able } \\
\text { groups }\end{array}$ & $\begin{array}{l}\text { Place of violence } \\
\text { in health facilities }\end{array}$ & $\begin{array}{l}\text { Source of } \\
\text { violence } \\
\text { initiation }\end{array}$ & $\begin{array}{l}\text { Causes } \\
\text { of vio- } \\
\text { lence }\end{array}$ & $\begin{array}{l}\text { Reporting } \\
\text { of violence }\end{array}$ & Consequences & $\begin{array}{l}\text { Mitiga- } \\
\text { tion } \\
\text { strategies }\end{array}$ \\
\hline Kitaneh M, Hamdan M & $\checkmark$ & $\checkmark$ & & $\checkmark$ & & $\checkmark$ & & \\
\hline $\begin{array}{l}\text { Algwaiz WM, Alghanim } \\
\text { SA }\end{array}$ & $\checkmark$ & $\checkmark$ & & $\checkmark$ & $\checkmark$ & $\checkmark$ & & \\
\hline Zafar W, Siddiqui E et al. & $\checkmark$ & $\checkmark$ & & $\checkmark$ & & $\checkmark$ & & \\
\hline $\begin{array}{l}\text { AbuAlRub RF, Al Khawal- } \\
\text { deh AT }\end{array}$ & $\checkmark$ & & & & $\checkmark$ & $\checkmark$ & & \\
\hline Tucker JD, Cheng Y et al. & & & & & $\checkmark$ & & $\checkmark$ & $\checkmark$ \\
\hline Kvas A, Seljak J & $\checkmark$ & & & $\checkmark$ & & & & \\
\hline Park M, Cho SH et al & $\checkmark$ & $\checkmark$ & & $\checkmark$ & & & & \\
\hline Hamdan M, Abu Hamra A & $\checkmark$ & $\checkmark$ & & $\checkmark$ & $\checkmark$ & $\checkmark$ & $\checkmark$ & \\
\hline $\begin{array}{l}\text { Pompeii LA, Schoenfisch } \\
\text { AL et al. }\end{array}$ & $\checkmark$ & & & & $\checkmark$ & $\checkmark$ & & \\
\hline Abed M, Morris E et al. & $\checkmark$ & $\checkmark$ & & $\checkmark$ & & & & \\
\hline Ferri P, Silvestri M et al. & $\checkmark$ & $\checkmark$ & $\checkmark$ & $\checkmark$ & & & & \\
\hline Bilici R, Sercan M et al. & & & & & $\checkmark$ & & & $\checkmark$ \\
\hline Sun T, Gao L & $\checkmark$ & & & & & & $\checkmark$ & \\
\hline $\begin{array}{l}\text { Shafran-Tikva S, Chinitz } \\
\text { D et al. }\end{array}$ & & & & $\checkmark$ & $\checkmark$ & & & \\
\hline $\begin{array}{l}\text { Rafeea F, Al Ansari A } \\
\text { et al. }\end{array}$ & $\checkmark$ & $\checkmark$ & & & & $\checkmark$ & $\checkmark$ & \\
\hline Wong AHW, Combellick J & & & $\checkmark$ & & $\checkmark$ & & & \\
\hline $\begin{array}{l}\text { Alsaleem SA, Alsabaani } \\
\text { A et al. }\end{array}$ & $\checkmark$ & $\checkmark$ & $\checkmark$ & & & & & \\
\hline Wang N, Wu D et al. & $\checkmark$ & $\checkmark$ & & & & & & \\
\hline $\begin{array}{l}\text { Honarvar B, Ghazanfari } \\
\mathrm{N} \text { et al. }\end{array}$ & $\checkmark$ & $\checkmark$ & & $\checkmark$ & $\checkmark$ & & & \\
\hline $\begin{array}{l}\text { Sachdeva S, Jamshed N } \\
\text { et al. }\end{array}$ & $\checkmark$ & $\checkmark$ & & $\checkmark$ & & $\checkmark$ & $\checkmark$ & \\
\hline Demirci Ş, Uğurluoğlu Ö & $\checkmark$ & $\checkmark$ & $\checkmark$ & $\checkmark$ & & & & \\
\hline $\begin{array}{l}\text { Davey K, Ravishankar V } \\
\text { et al. }\end{array}$ & & & & & $\checkmark$ & & $\checkmark$ & $\checkmark$ \\
\hline
\end{tabular}

protective strategies to combat the negative consequences of violence such as carrying a telephone, practising selfdefence, instructing perpetrators to stop being violent, self and social support, and limiting interactions with potential or known perpetrators of violence.

\section{Limitations}

There were many publications related to our topic on other sites. However, we selected only Pubmed and Scopus indexed journals to conduct this review because Pubmed is a free accessed website and Scopus for its popularity in medicine and social science. Another limitation of our review study is that we did not include those studies conducted on health workers other than doctors and nurses. Because doctors and nurses are directly involved in service delivery and are primary victims of healthcare workplace violence, most of the studies concerned about such a topic had taken samples from the doctor and nurse communities. However, to explain the ground reality and context, much more inclusion of other healthcare providers' studies are necessary. The study findings address patient and family as sources of violence, but does not address co-worker or non-client violence (Phillips 2016). Also, types of violence varies across countries. Different countries have different cultures and contexts of violence against physicians and nurses. Therefore, more context-based exploration of the causes of violence against physicians and nurses are warranted, especially in the low and middle income countries. 
Table 4 Proposed checklist for scientific research on violence against physicians and nurses (VPNCheck)

\begin{tabular}{|c|c|c|c|}
\hline SL No. & Heading & Points should be covered & Remarks \\
\hline 1. & Introduction & Must clearly present the background of the study with rationale for the study & \\
\hline 2. & Objective & Clearly state the objective of the study & \\
\hline 3. & Methodology & $\begin{array}{l}\text { Study design should be properly described. } \\
\text { Interviews should be taken away from the patient's bed preferably in separate room to explore real } \\
\text { picture better. } \\
\text { Education/Academic qualification should be explored side by side experiences/number of years } \\
\text { practices because both the issues are not the same. } \\
\text { Intern and trainee doctors should be included into the study because they faced the patient much } \\
\text { more than seniors in most of the tertiary care centres } \\
\text { Male nurses should be included though they were not the majority and females to explore the influ- } \\
\text { ence of gender variable better. } \\
\text { In the case of telephone interviews/ self-administered questionnaire, data quality should be checked } \\
\text { to address contamination or regression of mean bias. } \\
\text { Questionnaire selection should be comprehensive, covering all aspects of workplace violence } \\
\text { related to the selected population. } \\
\text { Qualitative studies should not be exclusively based on interview guide. It should be flexible after } \\
\text { contextualization based on ground reality. } \\
\text { Academic qualification/degree should be included and experience of work to know the relation of } \\
\text { educational qualification with the issue }\end{array}$ & $\begin{array}{l}\text { Include: witness- } \\
\text { based study. } \\
\text { Part-time staff } \\
\text { along with full- } \\
\text { time staff }\end{array}$ \\
\hline 4. & Result & $\begin{array}{l}\text { Issue related to fewer reports of violence came up repeatedly. One reason to be less likely to report } \\
\text { was due to ignorance from higher authority, a nurse or doctor representative. However, why the } \\
\text { issue of ignorance repeatedly came up, which leads to non-reporting by victims, was not explored } \\
\text { properly among selected articles. This issue should be focused on more. }\end{array}$ & \\
\hline 5. & Discussion & $\begin{array}{l}\text { Negative findings should be discussed along with common positive findings to explore the situation } \\
\text { as a whole. } \\
\text { Methodological limitations and recommendations for future studies based on own experience } \\
\text { should be included }\end{array}$ & \\
\hline 6. & Conclusion & $\begin{array}{l}\text { Strength and weakness of the current study should be written down along with limitations. } \\
\text { Conclusion should be exclusively based on study findings }\end{array}$ & \\
\hline
\end{tabular}

\section{Proposed checklist for scientific research on violence against physicians and nurses (VPNCheck)}

From our search strategy in the two most widely used databases and most appropriate search words, based on study objectives, we have initially critically assessed the selected articles. During the review, we explored specific gaps among included articles. We propose a checklist (Table 4) for scientific research on violence against physicians and nurses (VPNCheck).

\section{Conclusion}

Reduction of violence provides a better working environment for healthcare workers leading to a better healthcare delivery. Internal system-related factors should be considered first. Emergency departments prone to violent attacks should intervene first. Context-based research guiding strategies and policies are needed to reduce workplace violence against physicians and nurses.
Authors' contributions All authors wrote, read and approved the study for publication in JOPH. SC and KD: conceived the design and planning, review and writing. SRM writing and critical review. All authors provided their critical feedback and approved the final manuscript.

Funding Open access funding provided by Mid Sweden University.

Availability of data and material (data transparency) For literature review all selected articles are availabel in open system.

Code availability (software application or custom code) N/A

\section{Declarations}

Conflict of interest The authors declare that they have no conflict of interest.

Ethical statement This is a review study using scientific articles. We did not use any human or animal species in our study following Helsinki declarations and therefore the current study does not need any ethical permission.

Ethics approval Not required for a literature review.

Open Access This article is licensed under a Creative Commons Attribution 4.0 International License, which permits use, sharing, adaptation, distribution and reproduction in any medium or format, as long 
as you give appropriate credit to the original author(s) and the source, provide a link to the Creative Commons licence, and indicate if changes were made. The images or other third party material in this article are included in the article's Creative Commons licence, unless indicated otherwise in a credit line to the material. If material is not included in the article's Creative Commons licence and your intended use is not permitted by statutory regulation or exceeds the permitted use, you will need to obtain permission directly from the copyright holder. To view a copy of this licence, visit http://creativecommons.org/licenses/by/4.0/.

\section{References}

Abed M, Morris E, Sobers-Grannum N (2016) Workplace violence against medical staff in healthcare facilities in Barbados. Occupational Med (Oxford, England) 66(7):580-583. https://doi.org/ 10.1093/occmed/kqw073

AbuAlRub RF, Al Khawaldeh AT (2014) Workplace physical violence among hospital nurses and physicians in underserved areas in Jordan. J Clin Nurs 23(13-14):1937-1947. https://doi.org/10.1111/ jocn. 12473

Agarwal AK (2017) Patient-physician relationship; a keystone of Care in Emerging Health Care System. Psychol Behav Sci Int J 2(2). https://doi.org/10.19080/pbsij.2017.02.555582

Algwaiz WM, Alghanim SA (2012) Violence exposure among health care professionals in Saudi public hospitals: a preliminary investigation. Saudi Med J 33(1):76-82 https://pubmed.ncbi.nlm.nih. gov/22273653/

Alsaleem SA, Alsabaani A, Alamri RS, Hadi RA, Alkhayri MH, Badawi KK et al (2018) Violence towards healthcare workers: a study conducted in Abha City, Saudi Arabia. J Fam Community Med 25(3):188-193. https://doi.org/10.4103/jfcm.JFCM_170_17

Anand T, Grover S, Kumar R, Kumar M, Ingle GK (2016) Workplace violence against resident doctors in a tertiary care hospital in Delhi. Natl Med J India 29(6):344-348 https://pubmed.ncbi.nlm. nih.gov/28327484/

Ashton RA, Morris L, Smith I (2018) A qualitative meta-synthesis of emergency department staff experiences of violence and aggression. Int Emerg Nurs. https://doi.org/10.1016/j.ienj.2017.12.004

Azami M, Moslemirad M, YektaKooshali MH, Rahmati S, Soleymani A, Bigdeli Shamloo MB et al (2018) Workplace violence against Iranian nurses: a systematic review and meta-analysis. Violence Vict 33(6):1148-1175. https://doi.org/10.1891/0886-6708.33.6. 1148

Baydin A, Erenler AK (2014) Workplace violence in emergency department and its effects on emergency staff. Int J Emerg Mental Health 16(2):66-68. https://doi.org/10.4172/1522-4821.1000112

Bilici R, Sercan M, Izci F (2016) Levels of the staff's exposure to violence at locked psychiatric clinics: a comparison by occupational groups. Issues Mental Health Nurs 37(7):501-506. https://doi.org/ 10.3109/01612840.2016.1162883

Binmadi NO, Alblowi JA (2019) Prevalence and policy of occupational violence against Oral healthcare workers: systematic review and meta-analysis. BMC Oral Health 19(1):279. https://doi.org/10. 1186/s12903-019-0974-3

D’Ettorre G, Mazzotta M, Pellicani V, Vullo A (2018) Preventing and managing workplace violence against healthcare workers in emergency departments. Acta Biomedica 89(4-S):28-36. https://doi. org/10.23750/abm.v89i4-S.7113

Davey K, Ravishankar V, Mehta N, Ahluwalia T, Blanchard J, Smith J et al (2020) A qualitative study of workplace violence among healthcare providers in emergency departments in India. Int J Emerg Med 13(1):33. https://doi.org/10.1186/ s12245-020-00290-0
Demirci Ş, Uğurluoğlu Ö (2020) An evaluation of verbal, physical, and sexual violence against healthcare workers in Ankara, Turkey. J Forensic Nurs. https://doi.org/10.1097/jfn.0000000000 000286

Elston MA, Gabe J (2016) Violence in general practice: a gendered risk? Sociol Health Illness 38(3):426-441. https://doi.org/10. 1111/1467-9566.12373

Ferri P, Silvestri M, Artoni C, Di Lorenzo R (2016) Workplace violence in different settings and among various health professionals in an Italian general hospital: a cross-sectional study. Psychol Res Behav Manag 9:263-275. https://doi.org/10.2147/ PRBM.S114870

Gillespie GL, Gates DM, Miller M, Howard PK (2010) Workplace violence in healthcare settings: risk factors and protective strategies (CE). Rehabilit Nurs 35(5). https://doi.org/10.1002/j.2048-7940. 2010.tb00045.x

Hamdan M, Abu Hamra A (2015) Workplace violence towards Workers in the Emergency Departments of Palestinian hospitals: a crosssectional study. Hum Resour Health 13(1):28. https://doi.org/10. 1186/s12960-015-0018-2

Hills DJ, Joyce CM, Humphreys JS (2012) A national study of workplace aggression in Australian clinical medical practice. Med J Aust 197(6):336-340. https://doi.org/10.5694/mja12.10444

Honarvar B, Ghazanfari N, Shahraki HR, Rostami S, Lankarani KB (2019) Violence against nurses: a neglected and health-threatening epidemic in the university affiliated public hospitals in shiraz, Iran. Int J Occupational Environ Med 10(3):111-123. https://doi. org/10.15171/ijoem.2019.1556

Kitaneh M, Hamdan M (2012) Workplace violence against physicians and nurses in Palestinian public hospitals: a cross-sectional study. BMC Health Serv Res 12(1):469. https://doi.org/10.1186/ 1472-6963-12-469

Kumar M, Verma M, Das T, Pardeshi G, Kishore J, Padmanandan A (2016) A study of workplace violence experienced by doctors and associated risk factors in a tertiary care hospital of South Delhi, India. J Clin Diagn Res 10(11):LC06-LC10. https://doi.org/10. 7860/JCDR/2016/22306.8895

Kvas A, Seljak J (2015) Sources of workplace violence against nurses. Work (Reading, Mass) 52(1):177-184. https://doi.org/10.3233/ WOR-152040

Liu J, Gan Y, Jiang H, Li L, Dwyer R, Lu K et al (2019) Prevalence of workplace violence against healthcare workers: a systematic review and Meta-analysis. Occup Environ Med. https://doi.org/ 10.1136/oemed-2019-105849

McKay D, Heisler M, Mishori R, Catton H, Kloiber O (2020) Attacks against health-care personnel must stop, especially as the world fights COVID-19. Lancet 395(10239):1743-1745. https://doi.org/ 10.1016/S0140-6736(20)31191-0

Moher D, Liberati A, Tetzlaff J, Altman DG, Altman D, Antes G et al (2009) Preferred reporting items for systematic reviews and MetaAnalyses: The PRISMA Statement. PLoS Med Public Lib Sci. https://doi.org/10.1371/journal.pmed.1000097

Moola S, Munn Z, Tufanaru C, Aromataris E, Sears K, Sfetcu R, Currie M, Qureshi R, Mattis P, Lisy K, Mu P-F (2020) Chapter 7: Systematic reviews of etiology and risk. In: Aromataris E, Munn Z (eds). JBI Manual for Evidence Synthesis. JBI

Nagpal N (2017) Incidents of violence against doctors in India: can these be prevented? Natl Med J India 30(2):97-100 http://www. nmji.in/article. asp issn $=0970-258 X$; year $=2017$; volume $=30$; issue $=2 ;$ spage $=97 ;$ epage $=100 ;$ aulast $=$ Nagpal

Najafi F, Dalvandi A, Rahgozar M (2014) Workplace violence against Iranian nurses : a systematic review. J Health Promotion Manag 3(2). http://jhpm.ir/browse.php?a_id=243\&sid=1\&slc_lang=en

Park M, Cho SH, Hong HJ (2015) Prevalence and perpetrators of workplace violence by nursing unit and the relationship between 
violence and the perceived work environment. J Nurs Scholarsh 47(1):87-95. https://doi.org/10.1111/jnu.12112

Phillips JP (2016) Workplace violence against health Care Workers in the United States. N Engl J Med. https://doi.org/10.1056/NEJMr a1501998

Pompeii LA, Schoenfisch AL, Lipscomb HJ, Dement JM, Smith CD, Upadhyaya M (2015) Physical assault, physical threat, and verbal abuse perpetrated against hospital workers by patients or visitors in six U.S. Hospitals Am J Indust Med 58(11):1194-1204. https:// doi.org/10.1002/ajim.22489

Rafeea F, Al Ansari A, Abbas EM, Elmusharaf K, Abu Zeid MS (2017) Violence toward health Workers in Bahrain Defense Force Royal Medical Services' emergency department. Open Access Emerg Med: OAEM 9:113-121. https://doi.org/10.2147/OAEM.S147982

Raveel A, Schoenmakers B (2019) Interventions to prevent aggression against doctors: a systematic review. BMJ Open. https://doi.org/ 10.1136/bmjopen-2018-028465

Sachdeva S, Jamshed N, Aggarwal P, Kashyap SR (2019) Perception of workplace violence in the emergency department. J Emerg Trauma, Shock 12(3):179-184. https://doi.org/10.4103/JETS. JETS_81_18

Shafran-Tikva S, Chinitz D, Stern Z, Feder-Bubis P (2017) Violence against physicians and nurses in a hospital: how does it happen? A mixed-methods study. Israel J Health Policy Res 6(1):59. https:// doi.org/10.1186/s13584-017-0183-y

Stowell KR, Hughes NP, Rozel JS (2016) Violence in the emergency department. Psychiatr Clin N Am. https://doi.org/10.1016/j.psc. 2016.07.003

Sun T, Gao L, Li F, Shi Y, Xie F, Wang J et al (2017) Workplace violence, psychological stress, sleep quality and subjective health in Chinese doctors: a large cross-sectional study. BMJ Open 7(12). https://doi.org/10.1136/bmjopen-2017-017182
Tucker JD, Cheng Y, Wong B, Gong N, Nie JB, Zhu W et al (2015) Patient-physician mistrust and violence against physicians in Guangdong Province, China: a qualitative study. BMJ Open 5(10). https://doi.org/10.1136/bmjopen-2015-008221

Vorderwülbecke F, Feistle M, Mehring M, Schneider A, Linde K (2015) Aggression and violence against primary care physicians. Deutsches Aerzteblatt Online. https://doi.org/10.3238/arztebl. 2015.0159

Wang N, Wu D, Sun C, Li L, Zhou X (2018) Workplace violence in county hospitals in eastern China: risk factors and hospital attitudes. J Interpersonal Violence. https://doi.org/10.1177/08862 60518792242

Withnall A (2020) Coronavirus: why India has had to pass new law against attacks on healthcare workers. The Independent https:// www.independent.co.uk/news/world/asia/coronavirus-india-doctor-nurse-attack-law-modi-health-care-workers-a9480801.html. Accessed 5 Sept 2020

WHO (2016) Attacks on health care. https://www.who.int/activities/ responding-to-attacks-on-health-care. Accessed 20 Jan 2020

Wong AHW, Combellick J, Wispelwey BA, Squires A, Gang M (2017) The patient care paradox: an interprofessional qualitative study of agitated patient care in the emergency department. Acad Emerg Med 24(2):226-235. https://doi.org/10.1111/acem.13117

Zafar W, Siddiqui E, Ejaz K, Shehzad MU, Khan UR, Jamali S et al (2013) Health care personnel and workplace violence in the emergency departments of a volatile metropolis: results from Karachi, Pakistan. J Emerg Med 45(5):761-772. https://doi.org/10.1016/j. jemermed.2013.04.049

Publisher's note Springer Nature remains neutral with regard to jurisdictional claims in published maps and institutional affiliations. 